\title{
Using drifting passive echolocation loggers to study harbour porpoises in tidal-stream habitats
}

\author{
Ben Wilson*, Steven Benjamins, Jim Elliott \\ Scottish Association for Marine Science, Scottish Marine Institute, Oban, Argyll and Bute PA37 1QA, UK
}

\begin{abstract}
Moored passive acoustic detectors (e.g. C-PODs) are widely used to study harbour porpoise Phocoena phocoena distribution and relative abundance, but their use in tidal-stream habitats is complicated by the need for retrievable flow-resistant seabed fixings and the occurrence of flow-induced noise in the resultant data. In this study, we explored the use of a new method aimed at tidal-stream habitats, which are of increasing interest for marine renewable energy generation. Porpoise detectors (C-PODs) were attached to multiple drifters and repeatedly set adrift at a tidal-stream site in western Scotland during May 2010 and August 2011. Porpoise vocalisations were successfully detected under varying tidal conditions during approximately $63 \mathrm{~h}$ of drifting. Harbour porpoise distribution, as determined by the drifting detectors, was similar to that found using the traditional, yet more logistically intensive, visual and acoustic boat-based surveys and to an extent that found by moored C-PODs. Drifting detectors also mapped tidally driven spatiotemporal variability in ambient noise levels which could influence porpoise detection. In summary, drifters equipped with passive acoustic detectors offer a new, rapid and inexpensive tool for investigating porpoise occurrence and behaviour in tidal-stream habitats, and should be considered as part of a comprehensive marine mammal monitoring approach of these energetic environments in the context of marine renewable energy development and other industries.
\end{abstract}

KEY WORDS: Phocoena phocoena - Tidal stream • Marine renewable energy · Survey · Methodology $\cdot$ Drifter

\section{INTRODUCTION}

There is global and growing interest in exploiting marine renewable energy resources, including those associated with tidally driven water movement, particularly through narrow channels, around headlands or other areas of high current flow (sometimes exceeding $4 \mathrm{~m} \mathrm{~s}^{-1}$; WEC 2010). Numerous devices capable of extracting this energy are currently under development (e.g. EMEC 2012). In Scotland, there is considerable interest in further developing this industry, given Scottish Government policy objectives of meeting $100 \%$ of gross annual electricity demand from renewables by 2020 (SG 2011).

Concerns have been raised over potential effects of energy extraction on tidal-stream environments (e.g.

*Email: ben.wilson@sams.ac.uk
Inger et al. 2009, ICES WGMME 2011, Frid et al. 2012). Cetaceans are thought to be at risk from tidal energy devices in various ways, including collision with devices, disturbance during construction and/or device operation, noise emissions and habitat exclusion (Carter et al. 2008, ICES WGMME 2011). In order to address - and perhaps mitigate - these potential issues, we need to know how and why cetaceans are already using areas of interest for energy extraction, particularly in terms of small-scale distribution and habitat use. Currently, however, these issues are poorly understood, largely due to the difficulties of studying these highly mobile species in such energetic environments using standard techniques. Boat-based line-transect surveys, for example, are a standard method of assessing cetacean

() The Authors 2013. Open Access under Creative Commons by Attribution Licence. Use, distribution and reproduction are unrestricted. Authors and original publication must be credited. 
abundance, but animals are often difficult to see at the surface in tidal streams because of turbulence, standing waves and other intermittent features correlated with tidal flow. Furthermore, basic assumptions of the underlying distance sampling methodology may be violated, particularly in narrow channels between islands where currents may preclude an unbiased distribution of survey effort, edge effects may be significant, and water movement may cause animals to be non-randomly distributed relative to survey transects (Buckland et al. 2001, 2004). Given that the water containing the animals may be moving at an appreciable fraction of the speed of the survey vessel (potentially violating a central assumption of distance sampling that animals are stationary), counts and resulting density estimates may be severely biased depending on the direction of travel of both animals and the survey vessel relative to the current. These problems are less pronounced in aerial surveys because water speeds are insignificant compared to the aircraft's own speed. However, as most tidal sites are small $(<1$ to $10 \mathrm{~km}$ wide) and spatially heterogeneous, these high speeds will negatively bias sighting rates, exacerbated by poor sighting conditions at peak flow due to tidal turbulence. Any survey programme would also need to consider variability across tidal cycles, requiring significant effort. Visual observations from adjacent coastal vantage points can be informative but will be limited by the availability of suitable sites and thus biased towards particular locations and habitat features (Pierpoint 2008).

Acoustic monitoring faces comparable problems to shipboard visual observations or fixed vantage point approaches when applied in tidal streams. Such monitoring is typically carried out using either an array of hydrophone elements towed behind a survey vessel (offering good spatial coverage; e.g. Barlow \& Taylor 2005, Barlow 2006, Lewis et al. 2007) or by using moored autonomous acoustic recorders (offering good temporal coverage; e.g. Nieukirk et al. 2004, Simard et al. 2008, Van Parijs et al. 2009). Strong directional currents in tidal streams make it difficult to maintain hydrophone arrays in the correct configuration and generally to safely manoeuvre the survey vessel. Fixed autonomous acoustic recorders require robust moorings to resist the current, adding to mooring weight, complexity and cost, and potentially requiring larger vessels to safely deploy and retrieve them (Dudzinski et al. 2011). Furthermore, mooring deployment and retrieval may only be possible during brief periods of slack water. Strong currents may deflect recorders towards the substrate, increasing the risk of damage or loss, and/or interfere with their recording sensitivity. Tidal streams also produce elevated ambient sound levels which can mask cetacean sounds, particularly during peak tidal flow; finally, the rapid flow of water past the hydrophones in the detectors adds self-noise to the data (Au \& Hastings 2008, Bassett et al. 2010).

Because of these technical and methodological challenges, comparatively little is known about smallscale spatial distribution and habitat use of cetaceans in tidal streams. Nonetheless, with increasing numbers of tidal energy sites being considered for development in Europe, North America, New Zealand and elsewhere, studying cetaceans in these habitats is becoming more urgent, to:

(1) identify pre-development baseline levels of distribution and relative abundance across different temporal scales (tidal, diel, seasonal);

(2) determine which features of the tidal stream environment are especially attractive to cetaceans, and why; and

(3) inform what impacts might occur following construction and during long-term device operation.

Despite the problems outlined above, there are good reasons to consider using passive acoustic monitoring approaches, including their ability to record under conditions unsuitable for visual observations. Several passive acoustic click detectors/loggers are currently available, including the C-POD (Chelonia Ltd. see www.chelonia.co.uk/about_the_cpod.htm) and PAMBuoy ${ }^{\circledR}$ (Marine Instrumentation Ltd. see www.wildlifeacoustics.com/products/song-meter-sm2plus-submersible). These devices record evidence of vocalising porpoises and other small cetaceans by either recording actual sounds or by logging a record of each detected event. Of these devices, C-PODs are currently in widespread usage worldwide. C-PODs use waveform characteristics to identify odontocete echolocation clicks among other broadband sound sources. They log time, duration, centre frequency, loudness, inter-click interval and bandwidth of each received click. Although originally developed to detect high-frequency narrow-bandwidth clicks produced by species such as harbour porpoises Phocoena phocoena, C-PODs can also identify lowerfrequency/broad-band clicks produced by other odontocetes such as bottlenose dolphins Tursiops truncatus. Other parameters recorded include device tilt from vertical, ambient temperature and a crude proxy for background noise levels. C-PODs (and TPODs, their predecessors) have sufficient battery and memory capacity to remain deployed for up to 3 mo. These devices are widely used to investigate tempo- 
ral patterns in odontocete occurrence and distribution to study basic ecology as well as potential anthropogenic impacts of marine industries (Cox et al. 2001, Carlström 2005, Carstensen et al. 2006, Scheidat et al. 2011).

Harbour porpoises are listed under Annex II and IV of the EU Habitats Directive (European Commission 1992) due to the species' vulnerability to various anthropogenic threats including bycatch and disturbance. Under the Habitats Directive the UK has a responsibility to identify and evaluate the risk of key threats to the favourable conservation status of harbour porpoise (Pinn et al. 2009). Assessing distribution and habitat use of tidal-stream environments by porpoises, in the face of projected development of such sites for renewable energy extraction, is therefore important to assess potential risks associated with such developments to porpoises and other marine mammals.

Using C-PODs to study porpoises in tidal-stream sites is attractive in principle, but has been limited to date by problems associated with deployment, retrieval and flow noise. During a multi-year survey programme for the Scottish Government in inshore tidal-stream sites in Scottish waters, C-POD detectors were moored in several locations, and a number of problems became apparent (Wilson et al. 2012). First, it proved technically difficult to moor and retrieve detectors correctly in fast-flowing water. Second, strong currents regularly deflected detectors away from vertical, which was likely to bias any temporal comparison of porpoise occurrence across tidal phases. Third, mooring gear experienced substantial wear due to near-continuous water motion, occasionally leading to mooring failure and subsequent equipment loss. Fourth, during peak tidal flow, logged broad spectrum noise levels increased massively, regularly overloading the click detection capabilities of the detector and also potentially masking the porpoise calls themselves.

Here, we explore a potential solution to these mooring-related problems. We propose to detach passive echolocation loggers from their stationary moorings in moving water by fitting them into drifter assemblies and allowing them to drift freely with the current. While casting equipment adrift in strong currents is usually to be avoided, this approach has several potential advantages. First, by moving with the current, detectors no longer run the risk of being damaged by repeated collisions with the seabed. Second, while drifting at the same speed as the surrounding water, detectors would no longer experience the self-noise caused by water and sediment passing over the detector, resulting in cleaner recordings (Au \& Hastings 2008). Third, detectors sample a greater area than when moored. Finally, detectors can be collected downstream and redeployed upstream for repeat sampling effort akin to vessel surveys, but with the advantage that several can easily and inexpensively be deployed simultaneously. Conversely, drifting detectors can be expected to provide less predictable coverage of a given area. This study describes this methodology (hereafter referred to as Drifting Porpoise Detectors, DPDs) and compares results from test deployments with results from conventional techniques: boat-based visual and acoustic surveys and seabed-moored detectors (C-PODs).

\section{MATERIALS AND METHODS}

\section{Site selection}

The study was undertaken on the north-western coast of Scotland at Kyle Rhea, a narrow channel separating the Isle of Skye from the Scottish mainland $\left(57^{\circ} 14^{\prime} \mathrm{N}, 5^{\circ} 39^{\prime} \mathrm{W}\right)$. This area has been under investigation by at least 2 commercial companies for tidal energy extraction. The channel is approximately $4 \mathrm{~km}$ long and connects Loch Alsh to the north with the Sound of Sleat to the south (Fig. 1). The narrows are approximately $450 \mathrm{~m}$ wide at the most constrained point and can experience tidal streams of $>4 \mathrm{~m} \mathrm{~s}^{-1}$ during mean spring tides (UK Hydrographic Office 2008). Water depths reach approximately $30 \mathrm{~m}$ within Kyle Rhea but increase rapidly to $>80 \mathrm{~m}$ in more open waters at either end (UK Hydrographic Office 2013). The tidal regimen is characterised by strong, well-defined tidal currents running north-south (falling tide) and vice versa (rising tide), with only brief slack water periods between them (UK Hydrographic Office 2008). Whilst the main flow is predominantly laminar, the shorelines generate strong eddies, and opposing winds can produce elevated sea states and standing waves.

\section{Baseline visual/acoustic survey}

In 2010, Kyle Rhea was the focus of in-depth survey efforts funded by the Scottish Government (SG) to assess distribution and abundance of harbour porpoises and other marine mammals in a tidally active region (Wilson et al. 2012; Fig. 1 in the present article). First, a conventional line-transect survey was 


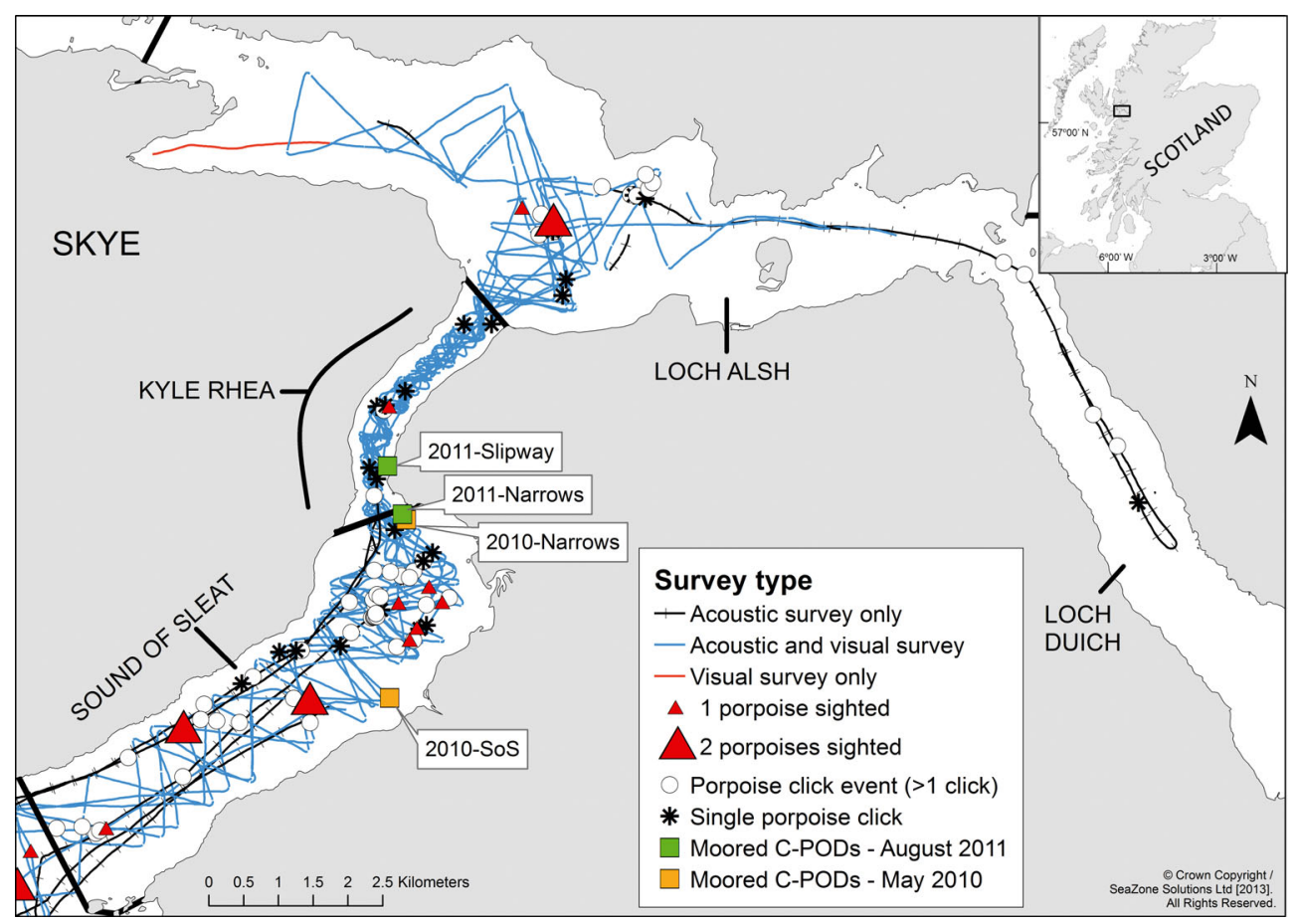

Fig. 1. Overview of 2010 survey effort and porpoise visual and acoustic detections (red triangles and white circles) obtained from RV 'Silurian' within Kyle Rhea and adjacent Loch Alsh, Loch Duich and the northern Sound of Sleat, Scotland. Solid lines denote area boundaries described in 'Materials and methods'. Note that Loch Alsh and the Sound of Sleat are connected to the open sea. Positions of moored C-PODs (2 each in 2010 and 2011) are also shown

performed using an adjusted-angle zigzag design, moving diagonally across Kyle Rhea with the tidal current and thereby achieving approximately equal coverage of the seabed and moving water column (Buckland et al. 2001, Wilson et al. 2012). This was done to minimise the risk of biasing porpoise sighting rates in fast-flowing waters. The survey was conducted from 13 to 21 May 2010, using the Hebridean Whale and Dolphin Trust (HWDT) 16 m RV 'Silurian'. Two visual observers were on watch during surveys (eye height approximately $4 \mathrm{~m}$ ), and each observed from the bow $\left(0^{\circ}\right)$ to the beam $\left(90^{\circ}\right.$, port and starboard, respectively) for up to $2 \mathrm{~h}$ at a time. Marine mammal sightings were recorded in a computer sightings database ('Logger 2000', Gillespie et al. 2010). Concurrent acoustic data were collected by a 2-element hydrophone array $(2$ high-frequency HS150 elements [Sonar Research \& Development], with highest sensitivity at $150 \mathrm{kHz}$ and a near-flat frequency response between 2 and $140 \mathrm{kHz}$ ). Each element was coupled to an adjacent pre-amplifier, providing $35 \mathrm{~dB}$ of gain. This array was towed $100 \mathrm{~m}$ behind the vessel (inter-element distance $0.25 \mathrm{~m}$ ). Porpoise echolocation click data were inspected in real time using purpose-written software (IFAW RainbowClick; Gillespie 1997) and stored for analysis. Visual surveys were conducted in daylight hours in sea states approximately equivalent to those expected for wind speeds of $\leq$ Beaufort 3 . On rare occasions when sea states exceeded 3, visual obser- vations ceased but acoustic surveys continued where possible. No survey effort was undertaken in sea states $>4$.

\section{Moored porpoise detectors}

During the DPD deployments in both 2010 and 2011, and the 2010 visual/acoustic boat survey, 2 additional C-PODs were moored using conventional means at $\sim 5 \mathrm{~m}$ from the seabed within and around Kyle Rhea in areas protected from the full strength of the tidal current (Fig. 1 and see Fig. 3). One site was monitored in both 2010 and 2011 (2010-Narrows and 2011-Narrows), but the second site (2010-SoS) was only monitored in 2010. To improve coverage in Kyle Rhea itself, in 2011 another C-POD was moored near the Glenelg-Kylerhea ferry slipway (2011-Slipway). Deployments lasted between approximately 2 and $4 \mathrm{~d}$ to coincide with fieldwork bouts.

\section{DPD construction and deployment}

The DPD concept was originally developed to coincide with the boat-based visual/acoustic monitoring survey in Kyle Rhea described above. The drifters were intended to be easily deployable from an independently operating small boat (rigid inflatable boat, RIB). As a test of concept, the following configuration 
was used: a standard porpoise detector (C-POD) was tethered to a weighted Lagrangian drogue designed for coastal environments (MicroStar ${ }^{\mathrm{TM}}$, Pacific Gyre Inc.; see www.pacificgyre.com/microstar-gps-drifter. aspx), stabilised at its base with a $4 \mathrm{~kg}$ weight. A noncompressible pellet float was used to keep the drogue upright. This was then secured to a surface float and a Dan-buoy, fitted with a Garmin ${ }^{\mathrm{TM}}$ GPS recorder and high-visibility flag (Fig. 2). The flotation was generally sufficient to keep the equipment from being entirely submerged by downwelling currents. The C-POD was attached to the drogue so that the acoustic receiver element remained facing upward, with both drifter and C-POD deployed at a depth of approximately $5 \mathrm{~m}$ below the surface. A depth of $5 \mathrm{~m}$ was arbitrarily chosen to keep the C-POD clear of surface waves while reducing the risk of snagging on the bottom in the shallows. This depth was also well clear of the likely $10 \mathrm{~m}$ depth ceiling of future operating turbines. C-PODs were programmed to remain on at all times irrespective of angle to vertical.

Deployment of DPDs occurred in 2 episodes. The first, on 18 and 20 May 2010, coincided with the visual/acoustic survey of Kyle Rhea, while the second, on 3 and 4 August 2011, was undertaken to expand coverage across a wider range of tidal phases. Two DPDs were used simultaneously during the 2010 deployment, and 4 were used in 2011. Multiple DPDs were deployed across the stream in quick succession (typically within minutes of one another) to maximise the area of the tidal race over which data could be collected. DPDs were deployed, monitored and retrieved using a RIB, itself drifting at a distance (300 to

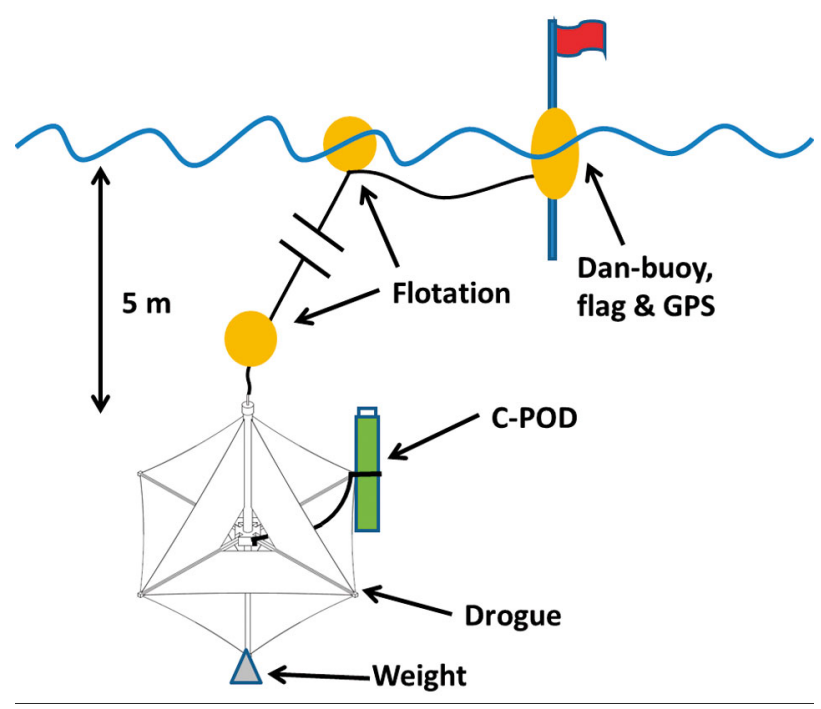

Fig. 2. Schematic of the experimental Drifting Porpoise Detector design
$500 \mathrm{~m}$ ) during deployments with engines and echosounder turned off. Following deployment, both DPDs and RIB tended to be displaced by tidal flows at similar rates. Decisions on where to (re-)deploy DPDs were not based on a particular survey design but instead sought to explore the drifter concept and sample the area across a range of tidal flow rates and directions. All DPD deployments occurred during daylight hours.

\section{Analysis}

Visual sightings data from the 2010 boat survey were analysed for species identity, group size and location. Acoustic data from the towed array were analysed using PAMGuard software (Gillespie et al. 2009; v. 1.11.02j BETA) to estimate harbour porpoise encounter rates across the study area, using filters appropriate for porpoise clicks (pre-filter: $40-180 \mathrm{kHz}$ Butterworth [Band Pass parameters: 4, 2]; trigger filter: $100-150 \mathrm{kHz}$ Chebychev [Band Pass parameters: $4,2])$. Potential porpoise click events were assessed visually by 2 independent researchers to confirm their identification. C-POD and GPS data from DPDs were downloaded and stored each day. C-POD data were processed using POD.exe software (v. 2.040, Chelonia Ltd.; see www.chelonia.co.uk/about_the_ cpod.htm). This program classified click data using a combination of 2 filters, the first determining the quality of each click train (on the basis of whether 2 or more consecutive clicks are part of a train, rather than unrelated events) on a scale of 'High', 'Moderate', 'Low' or 'Questionable'. The second determined the likely species identity of the click train on features such as frequency, inter-click interval and duration, assigning them to porpoises, other delphinid odontocetes, 'Sonar' and 'Unclassed'. Processing resulted in an assessment of whether each minute spent recording contained such porpoise click trains, and only click trains assigned to porpoises of 'Moderate' or 'High' quality were used. Depending on whether porpoise click trains were present, each minute of the deployment was therefore assigned a score of 1 (a Porpoise Positive Minute, PPM) or 0 (no click trains identified). C-POD data were analysed at the scale of individual minutes to achieve maximum temporal resolution. Porpoise click train detections were subsequently checked visually by experienced researchers to confirm correct identification. Processed C-POD data were subsequently matched with GPS coordinates and imported into ESRI ArcGIS ${ }^{\mathrm{TM}}$ v. 9.3.1. Data downloaded 
from GPS units were aggregated at a temporal resolution of $1 \mathrm{~min}$ to match C-POD data output. Consecutive sets of coordinates were used to calculate distances travelled and speeds reached by DPDs.

Spatial analyses were undertaken to compare the distribution of effort and porpoise detections by different survey methods using ArcGIS v. 9.3.1. It is important to note that this approach was based on locations of the detection platforms, rather than those of the detected animals themselves. A $500 \times 500 \mathrm{~m}$ grid was used to compare effort coverage and detection rates by the different survey methods across the area of interest. To compare methods, data were standardised according to the time (aggregated to entire minutes) each platform spent within each grid cell. Time-stamped GPS locations were used to calculate when each platform entered and left each grid cell, which allowed the total time spent within each grid cell over the course of the entire survey to be summed (rounded to the nearest minute). The number of individual porpoise detections was similarly summed per grid cell, thereby allowing the ratio of porpoise detections over total number of minutes surveyed to be calculated. All survey effort was stratified by tidal phase (rising versus falling), calculated on the basis of tide tables for Glenelg Bay immediately south of the Kyle Rhea narrows (NOC 2013). Only grid cells monitored for at least $10 \mathrm{~min}$ overall were considered in further analysis to avoid spuriously high detection rates during brief passes. Whenever multiple DPDs were present at the same time within the same grid cell, only the data of the first DPD entering a grid cell were used to avoid doublecounting of survey effort. Data from any additional DPDs were only used once the first DPD had left the grid cell. Where 2 or more DPDs entered a grid cell simultaneously, the decision on which dataset to discard was made on the basis of a random number generator. In cases when DPDs were close to each other but in adjacent grid cells, effort and detections were allocated to each grid cell despite the potential for overlapping coverage, as there was no practical means to assess whether 2 concurrent detections might be of the same animal.

Moored C-POD data were analysed in a similar manner to DPD data. Due to placement beside rather than in the flows, no moored C-POD was ever switched off by being pushed aside by the current (using standard settings), thereby providing uninterrupted coverage throughout deployment. For all CPODs (moored or drifting), any detections occurring within 10 min of each other were assumed to be part of a single encounter (Carstensen et al. 2006).

\section{RESULTS}

In this section we first present the results of 3 conventional techniques to investigate porpoise occurrence relative to the tidal stream area, followed by an exploration of the performance of DPDs.

\section{Visual/acoustic survey effort}

A total of $6 \mathrm{~d}$ of survey effort was undertaken by RV 'Silurian' in and around Kyle Rhea, Loch Alsh and the Sound of Sleat in 2010. Surveys began $1 \mathrm{~d}$ before full spring tide (14 May 2010) and finished approximately $1 \mathrm{~d}$ before full neap tide (21 May 2010). For the purposes of this study, the survey area was subdivided into 3 sections: (1) Kyle Rhea, (2) Lochs Alsh and Duich and (3) the northernmost section of the Sound of Sleat (Fig. 1). A total of $257.5 \mathrm{~km}$ of track line was surveyed both visually and acoustically in this area, while an additional $46.2 \mathrm{~km}$ was surveyed only acoustically, giving a total of $303.7 \mathrm{~km}$ survey effort across 277 separate transects (note that many such transects, such as those within Kyle Rhea itself, were by necessity relatively short). Vessel speed over ground (recorded at $10 \mathrm{~s}$ intervals) varied between 0.1 and $6.1 \mathrm{~m} \mathrm{~s}^{-1}$. The weather was generally favourable, with $>96 \%$ of survey work conducted in sea state $\leq 3$ (Table 1). Survey effort was divided approximately evenly between rising and falling tides.

Fourteen porpoises were sighted throughout the survey area across 11 events, with varying sighting rates between the 3 sections (Fig. 1). Most porpoise sightings (10 animals) occurred within the Sound of Sleat, over $116 \mathrm{~km}$ of effort. Only 1 sighting was recorded within the area of maximum flow in Kyle Rhea narrows despite $69 \mathrm{~km}$ of survey effort, $>50 \%$ of this in near-ideal sea conditions (sea state $\leq 1.5$ ). Sighting rates in Loch Alsh and Loch Duich were intermediate (Table 1). During falling tides, porpoises were sighted exclusively in the Sound of Sleat, whereas during rising tides, sightings also occurred elsewhere (Fig. 1). Most sightings occurred during falling tides.

During the boat-based acoustic survey, 60 porpoise click events (defined as at least 2 porpoise clicks within $1 \mathrm{~min}$, as identified by PAMGuard) were detected. Sea states did not have an obvious impact on acoustic detection rates. Detection distributions varied considerably by area and tidal phase (Table 2, Fig. 1), with particularly high detection rates in the Sound of Sleat $\left(0.49\right.$ click events $\mathrm{km}^{-1}$ during falling tide). Although most click events within Kyle Rhea 
Table 1. Phocoena phocoena. Summary of harbour porpoise sightings and sighting rates (no. porpoises $\mathrm{km}^{-1}$ ) by area at different sea states $(0-<1,1-<2,2-<3$ and $>3)$ and tidal phases during the May 2010 visual survey. Survey length is given in km

\begin{tabular}{|c|c|c|c|c|c|c|c|c|c|c|}
\hline \multirow[t]{2}{*}{ Area } & & \multicolumn{4}{|c|}{ Falling tide } & \multicolumn{4}{|c|}{ —Rising tide- } & \multirow[t]{2}{*}{ Total } \\
\hline & & $0-<1$ & $1-<2$ & $2-<3$ & $3+$ & $0-<1$ & $1-<2$ & $2-<3$ & $3+$ & \\
\hline \multirow{3}{*}{$\begin{array}{l}\text { Loch Alsh/ } \\
\text { Loch Duich }\end{array}$} & No. of porpoises & 0.0 & 0.0 & 0.0 & 0.0 & 0.0 & 0.0 & 3 & 0.0 & 3 \\
\hline & Survey length & 4.3 & 11.3 & 13.0 & 0.0 & 11.5 & 11.0 & 20.8 & 0.0 & 72.0 \\
\hline & Sighting rate & 0.0 & 0.0 & 0.0 & 0.0 & 0.0 & 0.0 & 0.14 & 0.0 & 0.04 \\
\hline \multirow{3}{*}{ Kyle Rhea } & No. of porpoises & 0.0 & 0.0 & 0.0 & 0.0 & 0.0 & 0.0 & 1 & 0.0 & 1 \\
\hline & Survey length & 11.2 & 16.5 & 14.1 & 3.8 & 7.3 & 5.6 & 10.8 & 0.0 & 69.3 \\
\hline & Sighting rate & 0.0 & 0.0 & 0.0 & 0.0 & 0.0 & 0.0 & 0.09 & 0.0 & 0.01 \\
\hline \multirow[t]{3}{*}{ Sound of Sleat } & No. of porpoises & 2 & 5 & 1 & 0.0 & 0.0 & 0.0 & 2 & 0.0 & 10 \\
\hline & Survey length & 11.4 & 24.4 & 17.9 & 15.2 & 0.0 & 13.6 & 29.8 & 3.7 & 116.1 \\
\hline & Sighting rate & 0.18 & 0.20 & 0.06 & 0.0 & 0.0 & 0.0 & 0.07 & 0.0 & 0.09 \\
\hline \multirow[t]{3}{*}{ Overall } & No. of porpoises & 2 & 5 & 1 & 0.0 & 0.0 & 0.0 & 6 & 0.0 & 14 \\
\hline & Survey length & 27.0 & 52.3 & 45.0 & 19.0 & 18.8 & 30.2 & 61.4 & 3.7 & 257.5 \\
\hline & Sighting rate & 0.07 & 0.10 & 0.02 & 0.0 & 0.0 & 0.0 & 0.10 & 0.0 & 0.05 \\
\hline
\end{tabular}

consisted of only a few clicks that were not organised in trains and were likely artefacts of background noise, 1 recognisable porpoise echolocation click sequence was recorded in the middle of the channel. Detections during falling tides were concentrated in the Sound of Sleat, particularly towards the northern boundary with Kyle Rhea (and, to a limited extent, within Kyle Rhea as well). During rising tides, no detections were made in the northernmost Sound of Sleat (nor indeed in Kyle Rhea), but instead detections occurred farther south in the Sound of Sleat as well as in Loch Alsh, northeast of Kyle Rhea (see Fig. 1 for details). Acoustic detections were aggregated on a minute-by-minute scale to facilitate comparison with PPMs detected by DPDs. No other cetacean species were sighted or detected during this study.

\section{Moored C-PODs}

Moored C-PODs were deployed for 2 to $4 \mathrm{~d}$. CPODs 2010-SoS and 2010-Narrows, and C-PODs 2011-Narrows and 2011-Slipway were deployed concurrently, respectively. In total, between 2 and 26 PPMs were detected by the various C-PODs during these deployments, which is relatively low when compared to other areas. Assuming that all detections within 10 min constitute a single encounter, moored C-PODs recorded a total of 33 encounters overall. Encounter rates (defined here as the number of encounters per number of minutes surveyed) varied by location and tidal phase, with 0.007 encounters $\mathrm{min}^{-1}$ recorded in the 2010-SoS site during falling tides, whereas only 0.001 encounters $\mathrm{min}^{-1}$ were recorded at the 2011-Slipway site during rising tides (Table 3, Fig. 3). Detection rates at the Narrows site varied considerably from one year to the next, suggesting that fine-scale habitat usage was not consistent in both years, although deployment durations were comparatively short in both cases (Table 3). The 2010 deployments occurred around neap tide, while 2011 deployments occurred during and immediately following spring tide, suggesting that porpoises preferred spring tide conditions at this particular location; however, insufficient data are currently available to develop this notion. No other odontocete species were detected during this study.

\section{DPDs}

The DPD concept proved to be successful, with acoustic data collected on 66 drifts with a combined duration of 63 h 21 min, ranging throughout Kyle 
Table 3. Summary of moored C-POD results from 2010 and 2011 deployments by tidal phase (FT: falling tide; RT: rising tide). See Total deployment durations were as follows: 2010-SoS (18 to 20 May: $47 \mathrm{~h} 39$ min); 2010-Narrows (16 to 20 May: $92 \mathrm{~h}$ $31 \mathrm{~min}$ ); 2011-Narrows (2 to 4 August: 47 h 52 min); 2011-Slipway (2 to 4 August: 47 h 28 min). See Fig. 1 for locations. PPM: Porpoise Positive Minutes

\begin{tabular}{|c|c|c|c|c|c|c|c|c|}
\hline & \multirow{2}{*}{\multicolumn{2}{|c|}{ 2010-SoS }} & \multicolumn{4}{|c|}{ - C-PODs } & \multirow{2}{*}{\multicolumn{2}{|c|}{ 2011-Slipway }} \\
\hline & & & \multicolumn{2}{|c|}{ 2010-Narrows } & \multicolumn{2}{|c|}{ 2011-Narrows } & & \\
\hline & FT & RT & FT & RT & FT & RT & FT & $\mathrm{RT}$ \\
\hline Deployment duration (min) & 1428 & 1381 & 2789 & 2762 & 1543 & 1329 & 1528 & 1320 \\
\hline No. of PPM & 18 & 8 & 5 & 0 & 20 & 6 & 0 & 2 \\
\hline No. of encounters & 10 & 5 & 5 & 0 & 8 & 3 & 0 & 1 \\
\hline Detection rate (PPM min ${ }^{-1}$ surveyed) & 0.013 & 0.006 & 0.002 & 0.000 & 0.013 & 0.005 & 0.000 & 0.002 \\
\hline $\begin{array}{l}\text { Encounter rate } \\
\text { (no. encounters } \min ^{-1} \text { surveyed) }\end{array}$ & 0.007 & 0.004 & 0.002 & 0.000 & 0.005 & 0.002 & 0.000 & 0.001 \\
\hline
\end{tabular}

Rhea over distances of up to $7.5 \mathrm{~km}$ (Fig. 3). Of these, 29 DPD drifts yielded successful detections of echolocating porpoises (see Table S1 in the Supplement at www.int-res.com/articles/suppl/n022p125_supp.pdf for a summary of DPD data by drift). Each DPD was retrieved and redeployed up to 8 times each day without significant difficulty. Deployments lasted up to $202 \mathrm{~min}$, during which DPDs experienced flow speeds up to $3.7 \mathrm{~m} \mathrm{~s}^{-1}$, although average current speeds were typically $<1.0 \mathrm{~m} \mathrm{~s}^{-1}$ (Table S1). DPDs typically slowed down when in tidal eddies or upon reaching the end of the ebb tidal jet in the Sound of Sleat. Sea states during deployment did not exceed sea state 3, although ebb tides flowing into the Sound of Sleat created discrete patches of turbulent water and profuse whitecaps. DPDs were exposed to varying tidal states which influenced travel speed and direction. Most drifts $(n=55)$ followed a roughly linear north-south track on a falling tide, while 12 flowed south-north on a rising tide (Fig. 3, Table S1). Eight drifts (all in the Sound of Sleat) ran essentially west-east, driven by the larger eddy systems generated by water flowing into and out of Kyle Rhea. In 5 instances where DPDs were released just before slack water, the current changed direction during their deployment and the DPDs were carried back towards their deployment location. In 2010, drifts occurred 1 to $3 \mathrm{~d}$ before full neap tide, whereas in 2011, drifts took place during and immediately after full spring tide. The use of multiple DPDs was intended to maximise spatial coverage, given that the DPDs' paths could not be controlled post-release. Where multiple DPDs were deployed consecutively, we allowed a 2 to 3 min interval between deployments to prevent immediate resampling of the same area. Despite this, some DPDs deployed in quick succession (several minutes apart) were carried along approximately the same trajectory down- stream, resulting in duplicated spatial coverage which had to be accounted for.

Overall, DPDs were highly successful in detecting porpoises during the course of their drifts among Kyle Rhea tidal-stream features. A total of 97 PPMs were identified, corresponding to approximately $2.5 \%$ of the entire deployment period (see Table S1). Assuming that all detections by the same DPD within 10 min constituted a single encounter, these 97 detections corresponded to 39 encounters across all DPDs. Encounter duration varied between 1 and $24 \mathrm{~min}$, with an average of $4.5 \mathrm{~min}$. Maximum recorded duration between consecutive PPMs within a single encounter was 9 min (by definition), corresponding to a downstream travel distance of approximately $584 \mathrm{~m}_{i}$ the longest distance covered within a single encounter was approximately $732 \mathrm{~m}$ (during $16 \mathrm{~min})$. Up to 2 encounters were observed during any one drift by any DPD. No other odontocete species were detected during this study.

PPM detection rates during individual drifts (defined as the number of PPMs per $\mathrm{km}$, per DPD) ranged from 0 to 7.96 (Table S1). Encounter rates (similarly defined as the number of encounters $\mathrm{km}^{-1}$ drifted) ranged between 0 and 1.96 encounters $\mathrm{km}^{-1}$ drifted (Table S1). These rates were considerably higher than those recorded by the visual and acoustic surveys (Tables $1 \& 2$ ). The visual and towed acoustic survey showed considerable spatial variability in porpoise presence across the area, with most sightings and acoustic detections occurring in the Sound of Sleat and almost none within Kyle Rhea (Fig. 1). This pattern was confirmed by the DPDs (Fig. 3). Both survey and DPD data also suggested an increase in detections during falling tides within the Sound of Sleat (Fig. 3).

Because drifters sampled in relation to water flow, they also provided information on detection rates relative to the variation in water flow rates. Overall, 

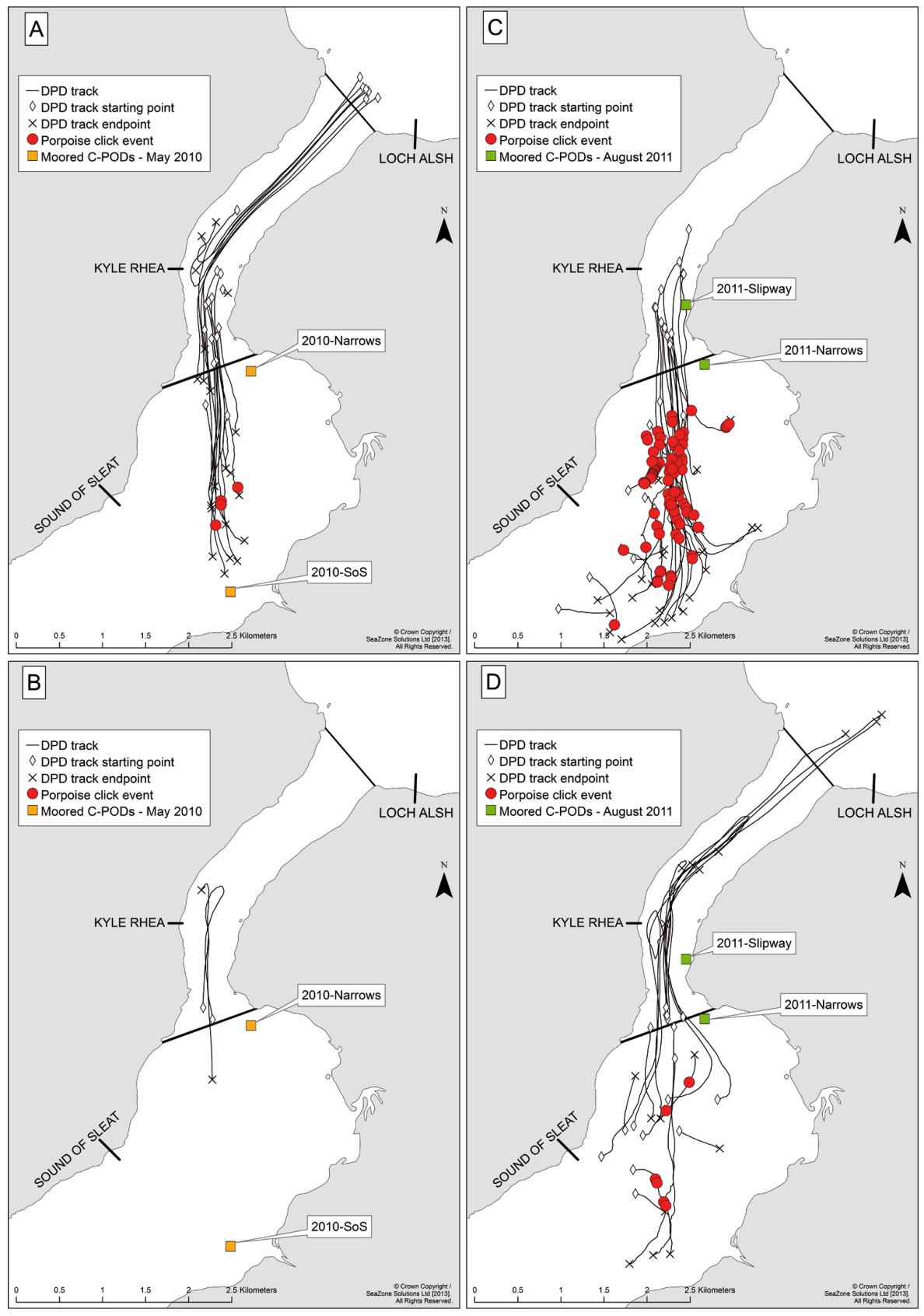

Fig. 3. Spatial distribution of Drifting Porpoise Detector (DPD) survey effort and porpoise detections in 2010 (A: falling tide; B: rising tide) and 2011 (C: falling tide; D: rising tide). DPD track starting and end points are denoted by white diamonds and black crosses, respectively. Moored C-POD locations (described in 'Materials and methods') are also indicated

most PPMs were recorded in relatively slowly moving water: more than $50 \%$ of PPMs were recorded at speeds of $<0.5 \mathrm{~m} \mathrm{~s}^{-1}$, and $>35 \%$ of all PPMs occurred at speeds of $\leq 0.3 \mathrm{~m} \mathrm{~s}^{-1}$. In contrast, only $6 \%$ of PPMs were detected at current speeds $\geq 1.5 \mathrm{~m} \mathrm{~s}^{-1}$ (max. $2.6 \mathrm{~m} \mathrm{~s}^{-1}$ ). DPDs detected no porpoises within the Kyle Rhea narrows despite also encountering relatively low flow rates there. The relationship between current speed and ambient noise levels was not linear, with very noisy minutes ( $>80 \%$ of minute lost) being recorded even at speeds $<0.5 \mathrm{~m} \mathrm{~s}^{-1}$. Given that such noisy minutes occurred across the entire range of reported current speeds at equally low rates (approximately $1 \%$ of the time), they are considered unlikely to have significantly impacted DPD porpoise detection capabilities. 

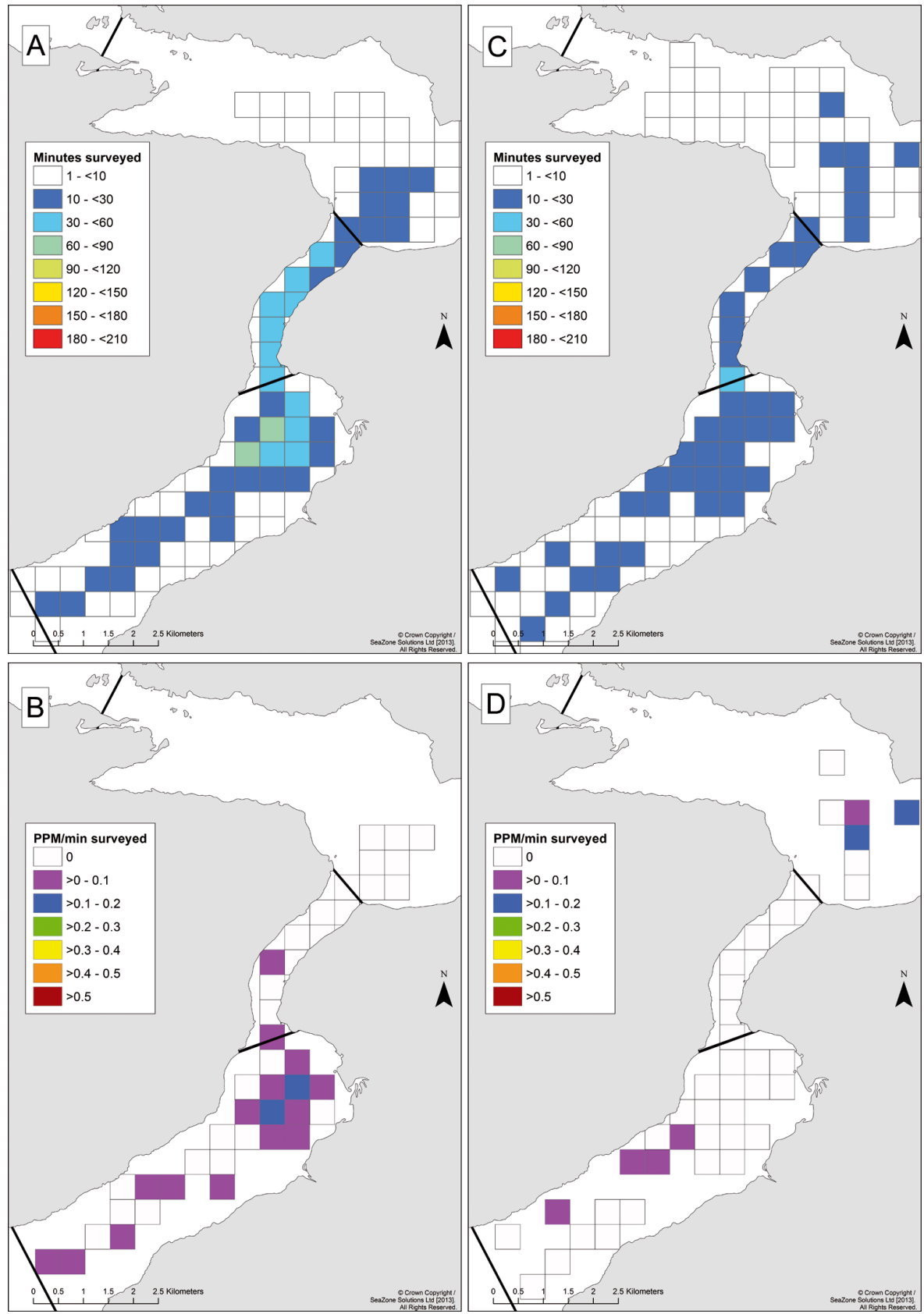

Fig. 4. Comparison of standardised acoustic survey effort $(A, C)$ and associated porpoise detection rates $(B, D)$ by RV 'Silurian' (A,B: falling tides; C,D: rising tides). Survey effort is expressed as minutes spent in a grid cell (A,C) and porpoise detection rates are expressed as Porpoise Positive Minutes (PPM) $\min ^{-1}(B, D)$. Only grid cells surveyed for $\geq 10$ min were used to estimate detection rates

\section{Comparing survey methods}

Although DPDs were not intended to provide systematic coverage of the entire survey area (unlike the visual/acoustic survey on RV 'Silurian'), they rapidly provided a picture of harbour porpoise presence within a specific area that was broadly comparable to that generated by more structured surveys, whilst using a smaller vessel and fewer personnel (and at approximately one-third of the cost of the vessel survey). Analysis of effort data indicated that DPDs provided more extensive total temporal coverage across different tidal states than the boat-based survey (Figs. 4 to 6), in terms of time spent monitoring a specific area (up to 181 min grid cell ${ }^{-1}$ using DPDs versus 42 min grid cell ${ }^{-1}$ during the survey). However, the 

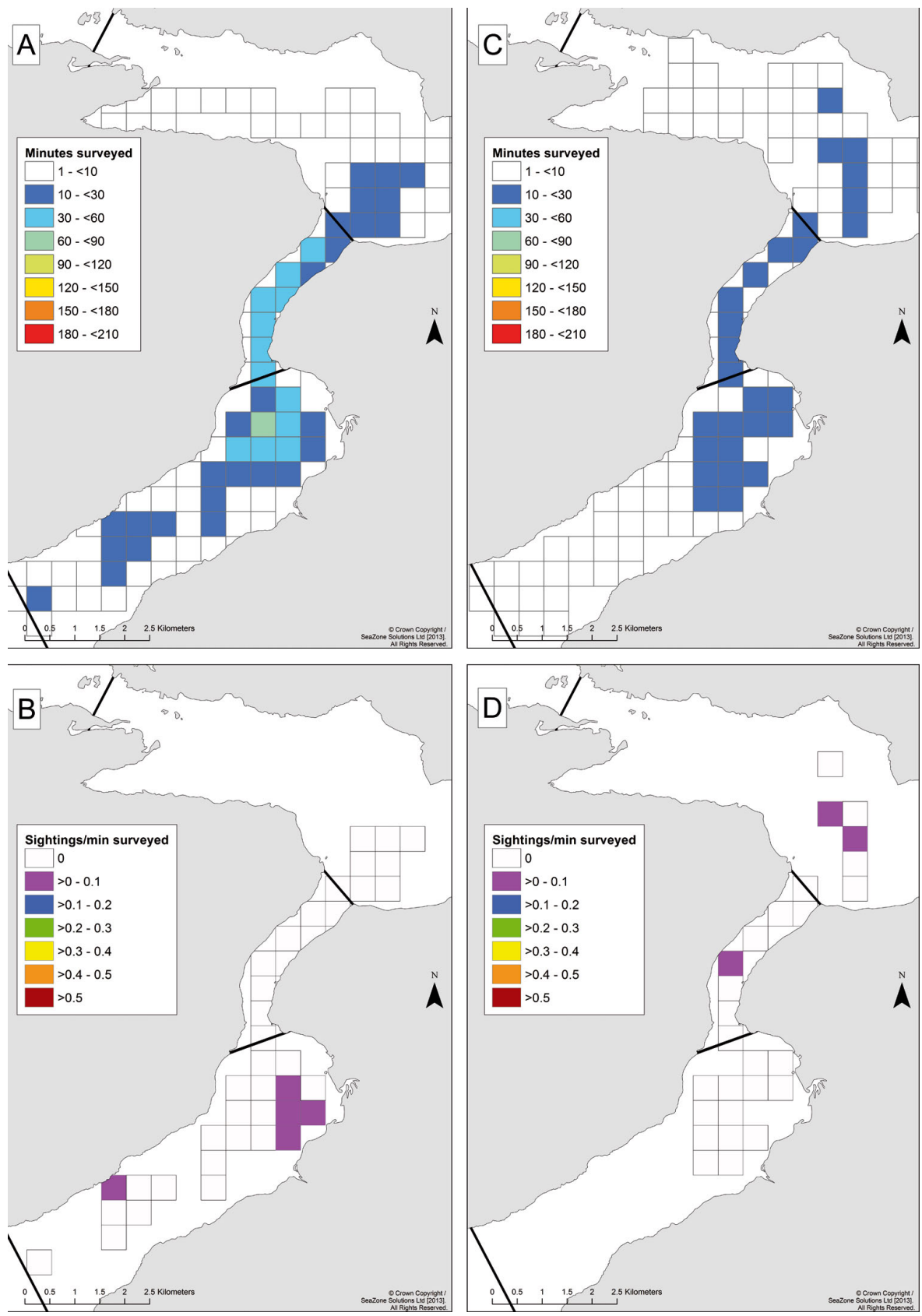

Fig. 5. Comparison of standardised visual survey effort $(A, C)$ and associated porpoise detection rates $(B, D)$ by RV 'Silurian' (A,B: falling tides; C,D: rising tides). Survey effort is expressed as minutes spent in a grid cell (A,C), and porpoise detection rates are expressed as sightings $\mathrm{min}^{-1}(\mathrm{~B}, \mathrm{D})$. Only grid cells surveyed for $\geq 10$ min were used to estimate detection rates

DPDs' spatial coverage was less extensive than that of the acoustic survey, because DPDs required moving water to sample adequately and thus did not cover the same areas outside the tidal-stream feature. All survey methods (boat-based surveys, moored C-PODs and DPDs) indicated a concentration of harbour porpoise detections in the Sound of Sleat, versus an almost-total absence of detec- tions within the Kyle Rhea narrows (Tables 1 to 4 , Figs. 4 to 6). Porpoise detections appeared to be concentrated at the northern end of the Sound of Sleat during falling tide while the southward-running tidal jet was present, but detection rates subsequently declined during rising tide. In contrast, although the area of Loch Alsh immediately to the northeast of the channel was not sampled by DPDs, the survey data 


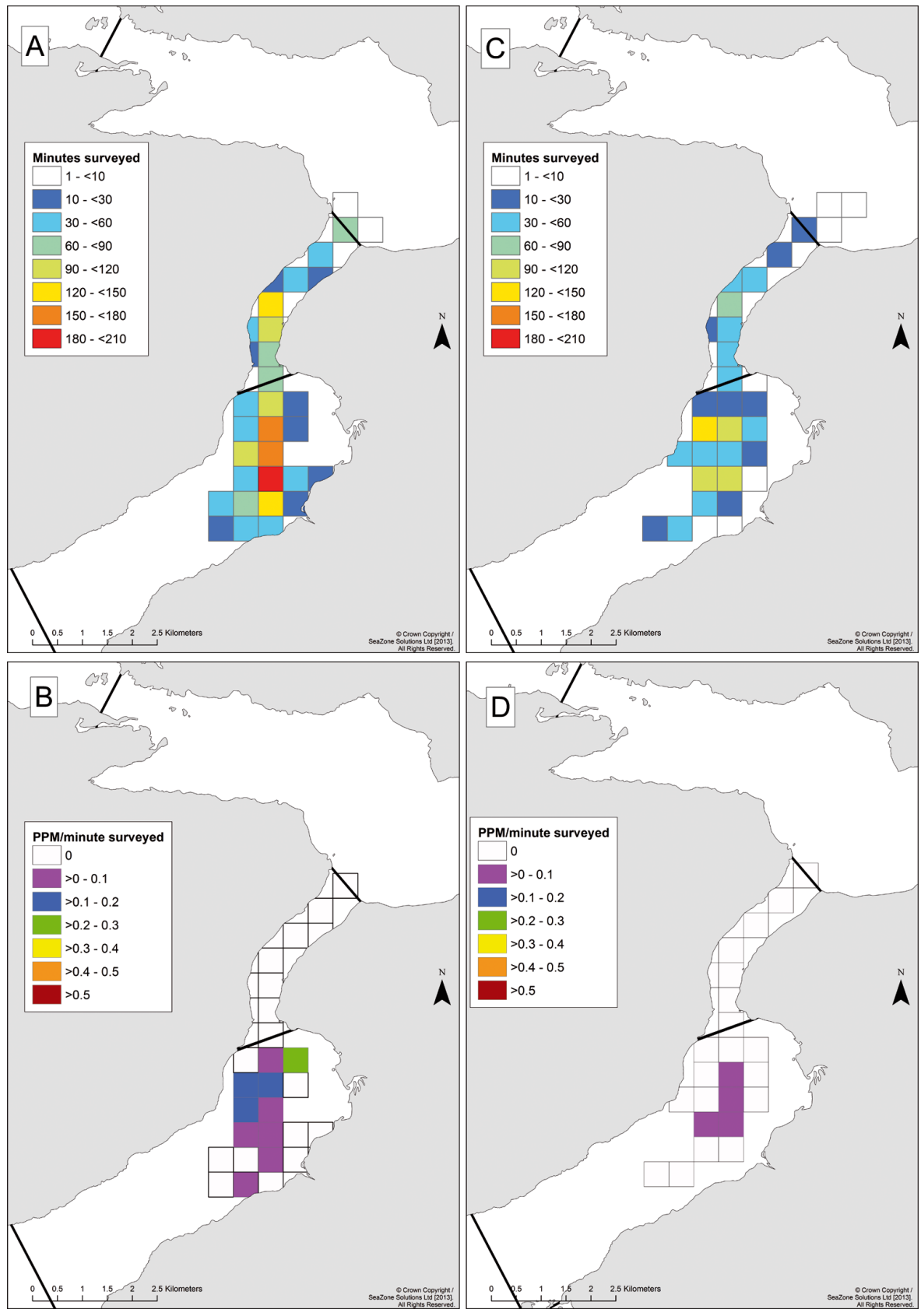

Fig. 6. Comparison of standardised Drifting Porpoise Detector (DPD) survey effort $(\mathrm{A}, \mathrm{C})$ and associated porpoise detection rates $(B, D)$ for all DPD drifts combined (A,B: falling tides; $C, D$ : rising tides). Survey effort is expressed as minutes spent in a grid cell $(A, C)$ and porpoise detection rates are expressed as Porpoise Positive Minutes (PPM) min ${ }^{-1}$ surveyed (B,D). Only grid cells surveyed for $\geq 10$ min were used to estimate detection rates

suggested increasing numbers of detections at rising tides in an area affected by a northwards-running tidal jet, similar to the one in the Sound of Sleat (UK Hydrographic Office 2008; Figs. 1, 4 to 6).

Results obtained by using DPDs therefore confirmed local distribution patterns of harbour porpoises generated by more traditional survey methods, at comparatively low levels of effort and cost.
This indicates that DPDs are a promising tool to study small cetaceans in these energetic environments.

\section{Opportunistic ambient sound mapping}

DPDs also detected undefined ambient sounds, likely generated by a combination of current-driven 
Table 4. Summary of potential survey methods likely to be used to assess tidal stream habitats for odontocetes such as harbour porpoises

\begin{tabular}{|c|c|c|}
\hline Method & Benefits & Drawbacks \\
\hline $\begin{array}{l}\text { Shore-based surveys } \\
\text { (visual) }\end{array}$ & $\begin{array}{l}\text { - Inexpensive } \\
\text { - High spatial resolution } \\
\text { - Flexible (able to exploit brief } \\
\text { - } \text { - Reather windows) } \\
\text { - Unlikely to disturb animals } \\
\text { - Allows observations of behaviour }\end{array}$ & $\begin{array}{l}\text { - Limited range } \\
\text { - Geographically limited (nearshore locations; good } \\
\text { vantage points required) } \\
\text { - Labour-intensive } \\
\text { - Unable to survey at night or in poor weather } \\
\text { - Abundance estimation problematic; non-standard } \\
\text { methods required (e.g. Cox et al. 2013) }\end{array}$ \\
\hline $\begin{array}{l}\text { Ship-based surveys } \\
\text { (visual/passive }\end{array}$ & $\begin{array}{l}\text { - Good spatial resolution (dependent on } \\
\text { scale of survey) } \\
\text { - Real-time data collection } \\
\text { - Allows for absolute abundance } \\
\text { estimation using standard methods }\end{array}$ & $\begin{array}{l}\text { - Limited temporal resolution ('snapshot') } \\
\text { - Weather-dependent } \\
\text { - Difficult/hazardous to manoeuvre vessel in fast currents } \\
\text { - Expensive } \\
\text { - Larger vessel may be needed } \\
\text { - Unable to survey at night or in poor weather } \\
\text { (only visual) } \\
\text { - Vessel may disturb animals } \\
\text { - Abundance estimation may be severely biased by } \\
\text { water movement }\end{array}$ \\
\hline Aerial surveys (visual) & $\begin{array}{l}\text { - Good for complex coastal areas } \\
\text { - Rapid coverage of broad areas } \\
\text { - Real-time data collection } \\
\text { - Allows for absolute abundance } \\
\text { estimation using standard methods } \\
\text { - Unlikely to disturb animals }\end{array}$ & $\begin{array}{l}\text { - Limited temporal resolution ('snapshot') } \\
\text { - Low sighting rates lead to poor abundance estimates } \\
\text { - Weather-dependent } \\
\text { - Comparatively expensive for small tidal areas }\end{array}$ \\
\hline $\begin{array}{l}\text { Moored passive } \\
\text { acoustic detectors }\end{array}$ & $\begin{array}{l}\text { - High temporal resolution } \\
\text { - Relatively inexpensive } \\
\text { - Unlikely to disturb animals }\end{array}$ & $\begin{array}{l}\text { - Point locations } \\
\text { - Limited detection range } \\
\text { - Easily lost/stolen/damaged } \\
\text { - Flow noise and data loss correlated with tidal feature } \\
\text { - Risk of pseudoreplication } \\
\text { - No real-time data collection } \\
\text { - Non-standard abundance estimation methods may } \\
\text { be required (e.g. Küsel et al. 2011, Kyhn et al. 2012) }\end{array}$ \\
\hline
\end{tabular}

sediment movement, water turbulence and other biological noise (Thorne 1990, Hildebrand 2009, Tonolla et al. 2010, Carter 2013). At times, these sounds quickly filled up the C-PODs' 1 min memory buffer (set at 4096 clicks min $^{-1}$ as default), thereby preventing any further data logging until the buffer was cleared at the start of the next minute. The presence and spatiotemporal distribution of elevated ambient sound were analysed by assessing what fraction of each minute was truncated by buffer saturation (while conscious that C-PODs were not originally designed for analysing ambient sound levels; Carter 2013, Chelonia Ltd. 2012 at www.chelonia.co.uk/ about_the_cpod.htm). To assess the impact of this 

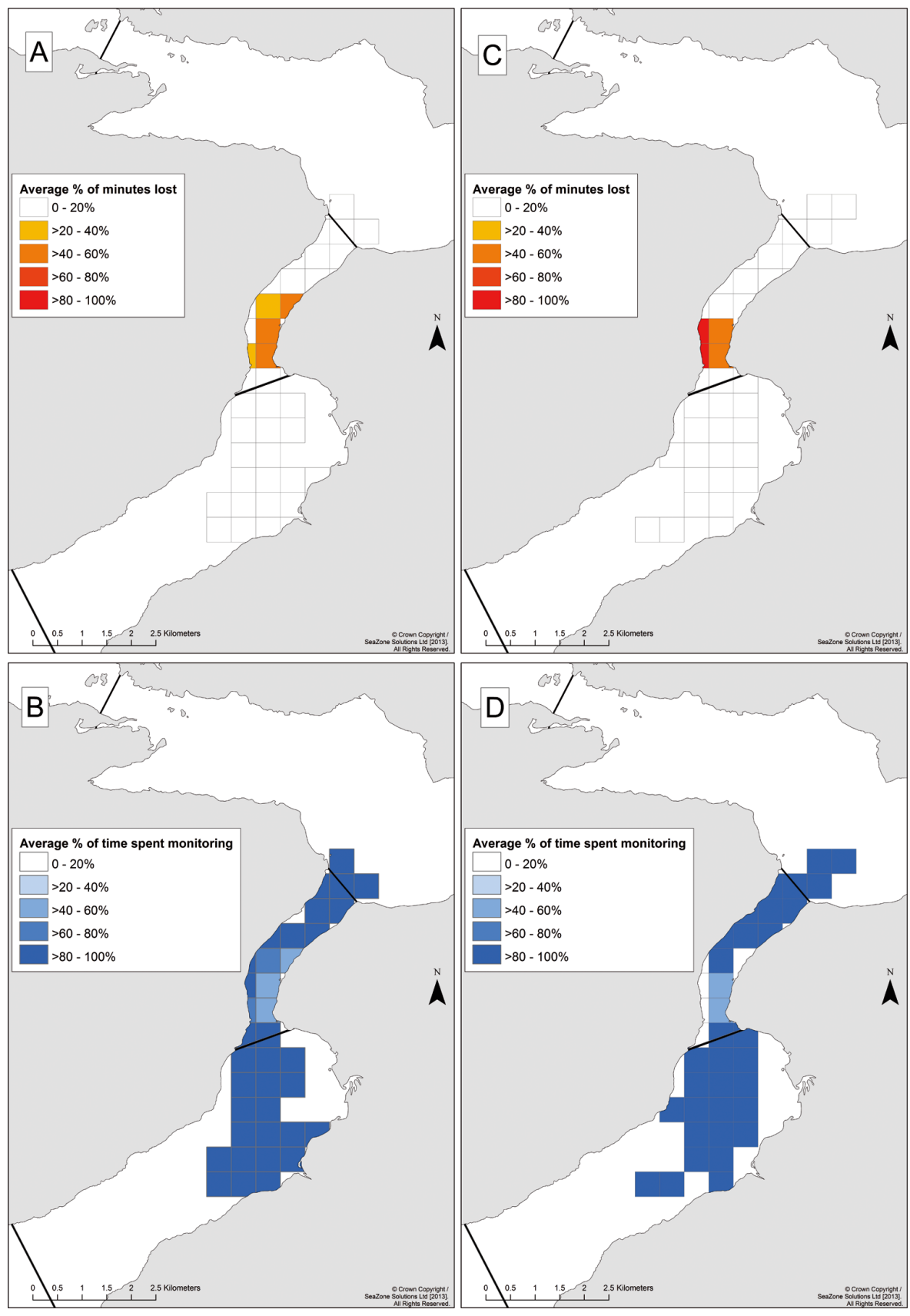

Fig. 7. Effects of high ambient noise levels on the logging abilities of C-PODs at (A,B) falling and (C,D) rising tides. (A,C) Average \% of each minute spent in each grid cell that was lost due to buffering problems (explained in the 'Results' and 'Discussion'). (B,D) Resulting converse \% of time C-PODs could successfully log without undue ambient noise interference

loss on detecting porpoises, the average fraction of whole minutes available for recording observed for that grid cell was calculated, summarised across deployments for rising and falling tides. The results showed that truncation was low (0 to $20 \%$ of each minute lost) during most deployments, but reached high levels ( $>80 \%$ of each minute lost) within the central Kyle Rhea for approximately 2 to $3 \mathrm{~h}$ during peak tidal flow (Fig. 7). At this point, a noisy area stretching $>1 \mathrm{~km}$ in length developed in the channel, within which the ability of C-PODs to record porpoise vocalisations was severely limited due to buffer saturation. Flow speed alone was not responsible for all of the sound and consequent truncation, as DPDs experienced similar speeds drifting south out of Kyle Rhea without registering significant truncation. The 
2011-Slipway moored C-POD recorded similar high levels of ambient sound which varied on a regular tidal cycle, implying that ambient sounds detected by DPDs were likely tidally driven rather than caused by other factors such as boat traffic. No porpoises were detected by the DPDs in the grid cells most impacted by noise at any time, including when ambient noise levels were very low (around slack tide, surveyed during 5 separate deployments; Table S1). C-PODs were able to record for close to $100 \%$ of the time throughout the rest of the deployment area, across different tidal phases and flow rates (Fig. 7), indicating that porpoise detection capabilities of DPDs were not inhibited by noise except in the central part of Kyle Rhea and at particular tidal phases (for a more in-depth review, see Carter 2013).

\section{DISCUSSION}

With the current global push to develop new sources of renewable energy, coastal and offshore tidal streams will inevitably become a potential target for energy extraction. As these technologies are unlikely to be entirely benign, there will be an associated need to determine whether vulnerable species also make use of these sites and what impacts associated with site development may occur. Surveying tidal-stream habitats presents many difficulties for conventional survey methodologies, however, primarily because of the rapid movement of the medium being surveyed. Studies of cetaceans in these sites are no exception, and the use of standard tools presents several difficulties that could lead to biased results. Here a new approach for monitoring odontocetes is proposed that makes deliberate use of the tidal stream itself, by securing passive acoustic monitoring equipment to drifters. This approach allows a tidal stream site to be investigated without the need for a large survey vessel or substantial flow-resistant moorings, or in combination with these more conventional approaches. This new method also allows multiple parcels of water to be surveyed simultaneously by deploying several drifters and so presents the potential for habitat use mapping in both (tidal) time and space.

The methods and results described in this paper represent an encouraging test of this drifting passive acoustics concept. We focussed our study on a site in western Scotland which is of interest to the tidal energy industry and within an area where harbour porpoises have been studied previously (Goodson et al. 1997). We used a widely used passive acoustic monitoring tool (C-POD) and attached this to an off- the-shelf drogue, GPS and inexpensive buoys and rope to make a drifter which we called a DPD. We then deployed several of these units, firstly concurrent with a standard visual and acoustics vessel survey and with moored C-PODs. We subsequently tested a fleet of 4 drifters to expand coverage across a wider area and range of tidal states.

Overall, the findings of the DPDs concurred with those of the combination of visual/acoustic vessel surveys and moored C-PODs. The DPDs, like the logistically more expensive vessel surveys, indicated that porpoises (expressed through acoustic and/or visual detections) were more prevalent in deeper waters of the Sound of Sleat rather than the narrow Kyle Rhea tidal-stream channel itself. In this channel, DPDs recorded no porpoise activity despite 41 drifts through all or part of it during flood, ebb and slack tides, while the vessel survey reported a single sighting and an (unrelated) acoustic detection. Similarly, the moored C-POD 2011-Slipway only recorded a single porpoise encounter. Each method therefore suggested low levels of usage by porpoises here. The fact that DPDs recorded no porpoises in Kyle Rhea, when the other 3 methods did, would be troubling were it not for the fact that they only made 1 porpoise detection each and therefore this result is attributable to the stochasticity of chance at such low occurrence rates. None of the Kyle Rhea detections by other platforms occurred while DPDs were nearby. Sighting and acoustic detection rates in Loch Alsh and Loch Duich, while much higher than the narrows, were somewhat lower than anticipated (compared with the Sound of Sleat) given that this area was historically targeted for porpoise research (Goodson et al. 1997). The similarity of spatial patterns found between sightings and acoustic detections (towed hydrophone, moored C-PODs and DPDs) was also reassuring because the reception of echolocation calls is reliant on animals vocalising and therefore open to potential bias if acoustic behaviour is related to habitat or some other spatially discrete variable.

Porpoise detection rates per $\mathrm{km}$ travelled were considerably higher for DPDs than for the visual and passive acoustic survey (Tables 1,2 \& S1). This discrepancy could be explained by the fact that the survey transects rapidly traversed areas of high porpoise abundance, while the more leisurely pace of the DPDs may have allowed them to detect more PPMs as they travelled through such areas. Some DPDs got caught in large eddy systems downstream of the ebb tidal jet and so traversed the same area more than once during a single deployment. For this reason, accurate and detailed position information is vital when using DPDs. 
Low abundance in the Kyle Rhea narrows compared to adjacent waters, based on both DPDs and vessel surveys, strongly suggests that this energetic habitat was not a focus for harbour porpoise activity. This finding agrees with that of Embling et al. (2010) and Booth et al. (2013), who found that porpoises over a coarser range of habitats on the west coast of Scotland tended to occur in areas of low current speed. Whether it is the depth, water motion or some other factor like bubble or sediment entrainment that is unattractive to porpoises remains unclear. Although the sample size from flood tides was small (Fig. 3B,D), DPD data suggested a difference in detection distribution between flood and ebb tides as well as a more general negative relationship between flow speed and animal detections. By further investigating these relationships, the nature of porpoise site use at tidal sites may become clearer. Such associations were less obvious from the vessel survey data because these were effectively collected despite the current and were therefore less easily linked to water motion. Moored C-PODs were better suited to reveal these trends, but the substantial flow-induced noise that they experienced at the precise times of tidalflow interest, together with their limited spatial coverage, weakens the confidence that can be put in the magnitude of such relationships.

The finding that porpoises do not occur in high abundance at the site of direct interest to renewable energy developers has implications for potential animal-industry interactions. Of most immediacy is the potential rate of injurious collisions between animals and turbine blades. Little is known about the mechanics of strikes, if they occur at all, but lower densities of animals would imply a less significant collision risk (Wilson et al. 2007). Our study indicates that porpoises in both Loch Alsh and the Sound of Sleat periodically seek out waters immediately outside the Kyle Rhea that are influenced by tidal jets, and that porpoises are not entirely absent from the narrows and use them from time to time. Being situated between 2 areas of high porpoise density, the channel likely serves to some degree as a corridor and is therefore of greater importance than the density might imply. Further, the tidally correlated detections of porpoises at either end of the narrows, particularly around the ebb tide outflow into the Sound of Sleat, suggests that while the high current itself may not be attractive to porpoises, its downstream consequences probably are. The implications of energy removal and increased turbulence from turbines on these activities may be another, less obvious source of interaction.
Using DPDs also made it possible to investigate the relationships between flow speed, flow direction and location against acoustic noise, as measured through the buffer saturation metric. While this feature was an unexpected (and initially inconvenient) outcome, it proved a useful by-product of the study. The occurrence of buffer saturation was correlated with tidal flow rate but also turned out to be discrete in space and time, being present only in 1 part of the tidal narrows around peak tidal flow times. This information would be useful when determining where to site (or, more importantly, where not to site) longer-term moored passive acoustic monitoring equipment.

It is unclear what effect (if any) these high ambient noise levels might have on the effective detection radius of DPDs. However, while the exact relationship between ambient noise and the detection ranges of the DPDs is unclear, ambient noise may make monitoring less efficient (as demonstrated by the buffer saturation). This is a potential problem for DPDs and, also, though rarely acknowledged, for studies using moored porpoise detectors. The present experiment did not allow for a robust assessment of how the effective detection radius of DPDs might change in response to varying levels of ambient noise. Reasonably precise localisation of animals relative to the survey trackline or detector is essential to estimate detection functions (i.e. the probability of detection as a function of distance from the trackline or detector position) and, thereby, to estimate absolute densities across the survey area (Buckland et al. 2001). For visual and acoustic surveys, this information was obtained during observations or initial data analysis, but no accurate measurement of distance between echolocating porpoises and the DPDs could be obtained. This means that DPD data as collected in this study, and as is also the case with moored detectors, could not be used to estimate absolute densities of porpoises. Various methods have been developed to estimate detection functions from solitary stationary passive acoustic detectors (e.g. Küsel et al. 2011, Kyhn et al. 2012), but these require additional information about animal behaviour and distribution that was not available here.

For this study, C-PODs were deployed with default settings, notably a memory buffer to log a maximum of 4096 clicks $\mathrm{min}^{-1}$. As discussed, sometimes this threshold was rapidly exceeded due to noise, preventing data logging for proportions of minutes. While this result proved unexpectedly useful (see above), it is not desirable in all recordings. Because DPD deployments were much shorter than that of a typical moored C-POD, filling up the total memory 
was a non-issue. In future, therefore, DPD buffer size could be set to the highest available setting (65536 clicks $\min ^{-1}$ ) or removed altogether to counter this elevated background noise problem associated with tidal streams.

Being drifters, the DPDs had no steerage or propulsion, and so their movements were solely influenced by deployment location and currents. For this study, this meant that the study area was not sampled equally. Whilst careful choice of deployment sites influences where drifters go, equal spatial sampling will never be possible. For example, the narrows with their fast flow tended to receive a higher density of drifter-related sampling but for a short time, while deeper areas with their slower water movements (e.g. the Sound of Sleat) received fewer drifters per unit area but for a longer time. In this proof-ofconcept study, the maximum consecutive number of minutes spent by a DPD within a $500 \times 500 \mathrm{~m}$ grid cell ranged from 1 to $54 \mathrm{~min}$, with an average of $15.2 \mathrm{~min}$ (in contrast, the survey vessel spent an average of only $1.9 \mathrm{~min}$ in each grid cell). The analysis presented here, taking into account drifter minutes per unit area, compensated for these differences but raised a pseudoreplication problem, in that each minute could not be considered to be independent, particularly when a DPD was effectively sampling the same packet of water as it moved over ground. This problem requires careful consideration in future applications if this method is to provide unbiased results, perhaps using refinements such as repeat deployments at the same locations but separated by sufficient time to avoid any risk of pseudoreplication. It is, however, worth noting that the same issue (though less obvious and rarely considered) also afflicts moored recorders if they are positioned in areas that experience intermittently flowing water with animals being moved by it.

This problem of unequal sampling in both drifting and moored recorders (as a result of the water moving with animals in it) also offers a potentially interesting tool to investigate how the animals themselves are behaving. In this study, it was unknown how porpoises behaved in relation to the water body. Animals could have moved around relative to the seabed (i.e. in map-relevant space), or could have ignored the seabed and simply moved around relative to the parcel of water they were in. It may be possible to explore this by using combinations of both moored and drifting passive acoustic monitoring equipment and comparing the duration of encounters between them with those from moored recorders in a non-tidal habitat. Animals, if moving relative to the seabed rather than the flow, should have acoustic contact times on the moored recorders more akin to those of a non-tidal site. In contrast, if animals are moving relative to a packet of water and oblivious to the ground, the drifter recordings should be more similar to those from the non-tidal site, and the acoustic contact duration on the moored devices should be somewhat shorter.

Whilst the inherently stochastic surveying process associated with using drifters means that this method cannot yet be used to provide robust abundance estimates (cf. Buckland et al. 2001, 2004), we suggest that it offers a useful new tool that may be used alongside or instead of existing methods to investigate aspects of tidal-stream site use by odontocetes (Table 4). In particular, it became apparent that drifters were comparatively inexpensive (less than a third of the cost) to deploy when compared to a shipbased (let alone an aerial) survey, while providing the equivalent of moored C-POD data across an entire tidal-stream site. The lack of fixed moorings also reduced the risk of device loss or damage and reduced the problem of flow noise. In our experience, multiple devices were easily deployed concurrently as well as consecutively to cover a wide area and investigate changes in the distribution of porpoises over a tidal cycle.

Several obvious refinements to the methodology described here are possible. First, we used C-PODs for their convenience and low cost over other passive acoustic monitoring equipment, but more sophisticated systems (e.g. SM2M+, Wildlife Acoustics, see www.wildlifeacoustics.com/products/song-meter-sm2plus-submersible; EAR, NOAA CRED, see www. pifsc.noaa.gov/cred/ear.php; and PAMBuoy ${ }^{\circledR}$, Marine Instrumentation Ltd., see www.pambuoy.co.uk) could collect actual acoustic data which would allow more in-depth analyses of marine mammal vocalisations and ambient noise. Second, we relied on visual contact to retrieve the drifters, which limited us to daylight hours. However, the application of satellite or mobile phone tracking technologies could have extended their operation into darkness and allowed multi-day deployments. This would allow for deploying many drifters at once and over much larger areas. This approach can be compared to using sonobuoys to detect cetacean vocalisations (e.g. Wade et al. 2011), but for high-frequency calls of species such as harbour porpoises. In Scotland, an obvious application would be the Pentland Firth, where considerable environmental monitoring investment is likely from the tidal-stream energy industry in the near future. This $30 \mathrm{~km}$ strait, connecting the North Sea and 
the North Atlantic between Orkney and mainland Scotland, is approximately $10 \mathrm{~km}$ wide and experiences both rapid tidal flows and substantial sea states. Although some aerial and ship-based surveys are already ongoing (e.g. MS 2010), accurately assessing marine mammal occurrence within this area provides many challenges, and none of the current studies is set up to explicitly consider the influence of tidal state. The use of DPDs in this essentially open-sea scenario could be highly informative. Of course, any future long-term deployment of such DPDs would have to ensure compliance with regulations to avoid them becoming a navigation hazard.

Finally, while this study focussed on using drifters to investigate odontocete occurrence in tidal-stream sites, similar untethered devices are already used in a wide variety of other oceanographic contexts (e.g. the global ARGO network; Freeland \& Cummins 2005). As a result of this trial, we feel that releasing passive acoustic monitoring equipment from the seabed or boats and attaching them to passive platforms such as drifters offers a new suite of potential opportunities to investigate odontocete occurrence and behaviour in a wide range of energetic environments.

Acknowledgements. The assistance provided by observers and crew of the HWDT RV 'Silurian', particularly N. van Geel, is gratefully acknowledged. J. Gordon (Sea Mammal Research Unit) and R. Leaper (International Fund for Animal Welfare) provided helpful input designing boat survey track methodology. I. Davies (Marine Scotland - Science), E. Tait (Marine Scotland) and G. Lees (Scottish Natural Heritage) provided project steerage. To seek feedback on the DPD concept, portions of this work were presented as a talk titled 'PODs adrift: a novel approach to monitoring cetaceans in tidal streams,' 26th Annual Conference of the European Cetacean Society, Galway, Ireland, March 2012, and at the 1st International Conference on the Environmental Interactions of Marine Renewable Energy Technologies, Kirkwall, Orkney, Scotland, UK, May 2012. Funding for this study was generously provided by Highlands and Islands Enterprise, the Scottish Government, the Natural Environment Research Council and the European Regional Development Fund. Three anonymous reviewers provided helpful comments and suggestions on an earlier version of this manuscript.

\section{LITERATURE CITED}

$\mathrm{Au}$ WWT, Hastings MC (2008) Principles of marine bioacoustics. Springer, New York, NY

Barlow J (2006) Cetacean abundance in Hawaiian waters estimated from a summer/fall survey in 2002. Mar Mamm Sci 22:446-464

Barlow J, Taylor B (2005) Estimates of sperm whale abundance in the northeastern temperate Pacific from a combined acoustic and visual survey. Mar Mamm Sci 21: $429-445$
Bassett C, Thomson J, Polagye B (2010) Characteristics of underwater ambient noise at a proposed tidal energy site in Puget Sound. IEEE OCEANS 2010 conference, Seattle, WA, 20-23 September 2010, p 1-8

> Booth CG, Embling C, Gordon J, Calderan SV, Hammond PS (2013) Habitat preferences and distribution of the harbour porpoise Phocoena phocoena west of Scotland. Mar Ecol Prog Ser 478:273-285

Buckland ST, Anderson DR, Burnham KP, Laake JL, Borchers DL, Thomas L (2001) Introduction to distance sampling: estimating abundance of biological populations. Oxford University Press, Oxford

Buckland ST, Anderson DR, Burnham KP, Laake JL, Borchers DL, Thomas L (2004) Advanced distance sampling: estimating abundance of biological populations. Oxford University Press, Oxford

Carlström J (2005) Diel variation in echolocation behaviour of wild harbour porpoises. Mar Mamm Sci 21:1-12

Carstensen J, Hendriksen OD, Teilmann J (2006) Impacts of offshore wind farm construction on harbour porpoises: acoustic monitoring of echolocation activity using porpoise detectors (T-PODs). Mar Ecol Prog Ser 321: 295-308

Carter CJ (2013) Mapping background underwater-sound in areas suitable for tidal-energy extraction in Scotland's coastal waters and the potential audibility of tidal-stream devices to marine mammals. $\mathrm{PhD}$ dissertation, University of the Highlands and Islands/University of Aberdeen

Carter CJ, Wilson B, Black K (2008) Marine renewable energy devices: a collision risk for marine mammals? In: Evans PGH (ed) Carter CJ, Wilson B, Black K (2008) Marine renewable energy devices: a collision risk for marine mammals? In: Evans PGH (ed) Workshop: Offshore wind farms and marine mammals: Impacts \& methodologies for assessing impacts. 21st Annu Meeting of the European Cetacean Society, 21-25 April, San Sebastian, Spain. ECS Newsl 49 (Spec Issue):60-62

Cox TM, Read AJ, Solow A, Tregenza N (2001) Will harbour porpoises (Phocoena phocoena) habituate to pingers? J Cetacean Res Manag 3:81-86

Cox MJ, Borchers DL, Kelly N (2013) nupoint: an R package for density estimation from point transects in the presence of nonuniform animal density. Methods Ecol Evol 4: 589-594 doi: 10.1111/2041-210X.12058

> Dudzinski KM, Brown SJ, Lammers M, Lucke K and others (2011) Trouble-shooting deployment and recovery options for various stationary passive acoustic monitoring devices in both shallow- and deep-water applications. J Acoust Soc Am 129:436-448

> Embling CB, Gillibrand PA, Gordon J, Shrimpton J, Stevick PT, Hammond PS (2010) Using habitat models to identify suitable sites for marine protected areas for harbour porpoises (Phocoena phocoena). Biol Conserv 143:267-279

EMEC (European Marine Energy Centre) (2012) Tidal devices. www.emec.org.uk/marine-energy/tidal-devices/ \#loaded (accessed 4 March 2013)

European Commission (2009) Council Directive 92/43/EEC of 21 May 1992 on the conservation of natural habitats and of wild fauna and flora. http://eur-lex.europa.eu/ LexUriServ/LexUriServ.do?uri=CELEX:31992L0043:EN: HTML (accessed 28 October 2013)

Freeland HJ, Cummins PF (2005) Argo: a new tool for environmental monitoring and assessment of the world's oceans, an example from the N.E. Pacific. Prog Oceanogr 64:31-44 
Frid C, Andonegi E, Depestele J, Judd A, Rihan D, Rogers SI, Kenchington E (2012) The environmental interactions of tidal and wave energy generation devices. Environ Impact Assess 32:133-139

Gillespie D (1997) An acoustic survey for sperm whales in the Southern Ocean sanctuary conducted from the R/V Aurora Australis. Rep Int Whal Comm 47:897-908

Gillespie D, Mellinger DK, Gordon J, McLaren D and others (2009) PAMGUARD: semiautomated, open source software for real-time acoustic detection and localization of cetaceans. J Acoust Soc Am 125:2547

Gillespie D, Leaper R, Gordon J, MacLeod K (2010) An integrated data collection system for line transect surveys. J Cetacean Res Manag 11:217-227

Goodson AD, Amundin M, Mayo RH, Newborough D and others (1997) Aversive sounds and sound pressure levels for the harbour porpoise (Phocoena phocoena): an initial field study. ICES Theme Session (Q) By-catch of marine mammals. Baltimore, MD, September 1997, p 1-5

Hildebrand JA (2009) Anthropogenic and natural sources of ambient noise in the ocean. Mar Ecol Prog Ser 395:5-20

ICES Working Group on Marine Mammal Ecology (WGMME) (2011) Report of the Working Group on Marine Mammal Ecology (WGMME), 21-24 February, Berlin, Germany. ICES CM 2011/ACOM:25. ICES, Copenhagen

Inger R, Attrill MJ, Bearhop S, Broderick AC and others (2009) Marine renewable energy: potential benefits to biodiversity? An urgent call for research. J Appl Ecol 46: 1145-1153

Küsel ET, Mellinger DK, Thomas L, Marques TA, Moretti D, Ward J (2011) Cetacean population density estimation from single fixed sensors using passive acoustics. J Acoust Soc Am 129:3610-3622

Kyhn LA, Tougaard J, Thomas L, Duve LR and others (2012) From echolocation clicks to animal density-acoustic sampling of harbor porpoises with static dataloggers. J Acoust Soc Am 131:550-560

Lewis T, Gillespie D, Lacey C, Matthews J and others (2007) Sperm whale abundance estimates from acoustic surveys of the Ionian Sea and Straits of Sicily in 2003. J Mar Biol Assoc UK 87:353-357

Marine Scotland (2010) Strategic bird surveys in the Pentland Firth and Orkney waters development area. Marine Scotland Topic Sheet No. 85v1. Available at www.scotland. gov.uk/Resource/Doc/295194/0109729.pdf (accessed 21 March 2013)

Nieukirk SL, Stafford KM, Mellinger DK, Dziak RP, Fox CG (2004) Low-frequency whale and seismic airgun sounds recorded in the mid-Atlantic Ocean. J Acoust Soc Am 115:1832-1843

NOC (National Oceanography Centre) (2013) POLTIPS-3 Tidal prediction software. Available at http://noc.ac.uk/ tag/poltips (accessed 26 July 2013)

Pierpoint C (2008) Harbour porpoise (Phocoena phocoena) foraging strategy at a high energy, near-shore site in southwest Wales, UK. J Mar Biol Assoc UK 88:1167-1173

Editorial responsibility: Brendan Godley, University of Exeter, Cornwall Campus, UK
Pinn E, Tasker M, Mendes S, Goold J (2010) Maintaining favourable conservation status of harbour porpoise in UK waters. Joint Nature Conservation Committee paper JNCC 09 P21a. Joint Nature Conservation Committee, Peterborough, 1-17. http://jncc.defra.gov.uk/PDF/comm 09P21a.pdf (accessed October 18 2013)

> Scheidat M, Tougaard J, Brasseur S, Cartensen J, van Polanen Petel T, Teilmann J, Reijnders P (2011) Harbour porpoises (Phocoena phocoena) and wind farms: a case study in the Dutch North Sea. Environ Res Lett 6:025102, doi:10.1088/1748-9326/6/2/025102

Scottish Government (SG) (2011) Renewables revolution aims for $100 \%$. Available at www.scotland.gov.uk/ News/Releases/2011/05/18093247 (accessed 21 March 2013)

Simard Y, Roy N, Gervaise C (2008) Passive acoustic detection and localization of whales: effects of shipping noise in Saguenay-St. Lawrence Marine Park. J Acoust Soc Am 123:4109-4117

Thorne PD (1990) Seabed generation of ambient noise. J Acoust Soc Am 87:149-153

- Tonolla D, Acuna V, Lorang MS, Heutschi K, Tockner K (2010) A field-based investigation to examine underwater soundscapes of five common river habitats. Hydrol Processes 24:3146-3156

UK Hydrographic Office (2008) Admiralty sailing directions. West Coast of Scotland Pilot - West coast of Scotland from Mull of Galloway to Cape Wrath including the Hebrides and off-lying islands. Publication NP66. UK Hydrographic Office, Taunton

UK Hydrographic Office (2013) UK Admiralty Chart 2540 Loch Alsh and Approaches. UK Hydrographic Office, Taunton

Van Parijs SM, Clark CW, Sousa-Lima RS, Parks SE, Rankin S, Risch D, Van Opzeeland IC (2009) Management and research applications of real-time and archival passive acoustic sensors over varying temporal and spatial scales. Mar Ecol Prog Ser 395:21-36

Wade PR, De Robertis A, Hough KR, Booth R and others (2011) Rare detections of North Pacific right whales in the Gulf of Alaska, with observations of their potential prey. Endang Species Res 13:99-109

Wilson B, Batty RS, Daunt F, Carter C (2007) Collision risks between marine renewable energy devices and mammals, fish and diving birds. Strategic Environmental Assessment for Wave and Tidal Energy. Appendix C7B. Scottish Government, Edinburgh

Wilson B, Benjamins S, Elliott J, Gordon J, Macaulay J, Calderan S, van Geel N (2012) Estimates of collision risk of harbour porpoises and marine renewable energy devices at sites of high tidal-stream energy. Scottish Government, Edinburgh

WEC (World Energy Council) (2010) 2010 survey of energy resources. Available at www.worldenergy.org/ publications/2010/survey-of-energy-resources-2010 (accessed 24 June 2013)

Submitted: April 24, 2013; Accepted: August 13, 2013 Proofs received from author(s): October 30, 2013 